retain the rich diversity and quality of dental practitioners that we now have then we may need to think about structuring employment to make it easier for those who choose to work part-time. This may include greater use of job sharing and salaried positions.'

Importantly, new legislation relating to flexible parental leave might change working patterns in the UK and give women, for the first time, a real choice over work-life balance. ${ }^{6}$ It is expected that in 2015 flexible leave will be enacted, meaning that while women have to take off the first two weeks after birth for recovery, the remaining 50 weeks of maternity leave can be shared between both mother and father as they see fit. Shared parental leave was first introduced in Sweden in 1974, though state money incentives introduced in 1995 dramatically increased the uptake of 'daddy leave'. Now it is not seen as unusual but something 'everyone does', ${ }^{7}$ with the majority of fathers using at least a third of shared parental leave. Health minister Anna Soubry recently claimed that the increase in women studying medicine in the UK has 'unintended consequences' - putting a strain on the NHS when they marry, have children and work part-time. ${ }^{8}$ Perhaps the forthcoming new parental leave policy will invoke cultural change, so that such 'unintended consequences' are not only a female issue, but a shared problem for men and women in the workforce regardless of gender.

Inevitably the future workforce will have different requirements and now is the time to decide how to meet its needs. There is still a way to go before gender equality is reached in terms of seniority and pay, but in many ways it is up to female dentists to shape their own future, actively engaging in and contributing to the dental community. According to Judith Husband 'we live in a privileged point in time as women in the UK'.

1. Seward M. The gender challenge. Br Dent J 2000; 189: 525

2. Health and Social Care Information Centre. NHS dental statistics for England: 2011-2012. London: HSIC, 2012. Online statistics available at www.hscic.gov.uk/catalogue/PUB07163 (accessed August 2013)

3. General Dental Council. Personal correspondence, 2 September 2013.

4. Robinson P G, Patrick A, Newton T. Modelling the dental workforce supply in England. Sheffield: University of Sheffield, 2011

5. Newton J T, Buck D, Gibbons D E. Workforce planning in dentistry: The impact of shorter and more varied career patterns. Community Dent Health 2001; 18: 236-241.

6. Reform of flexible parental leave. Online information on legislation available at https://www.gov.uk/government/news/reformof-flexible-parental-leave (accessed September 2013).

7. Bennhold K. In Sweden, men can have it all. New York Times, 2010. Online article available at www.nytimes.com/2010/06/10/ world/europe/10iht-sweden.html?pagewanted=all\&t_r=1\&t (accessed September 2013).

8. Dominiczak P. Female doctors who work part time after having children put NHS under strain. UK: Telegraph, 2013. Online article available at http://www.telegraph.co.uk/health/healthnews/10101276/Female-doctors-who-work-part-time-afterhaving-children-put-NHS-under-strain.html (accessed August 2013).

BY LAURA PACEY

\section{FEWER TEASPOONS OF SUGAR A DAY WILL CUT DECAY}

New research from Newcastle University recommends cutting down on sugar as part of a global initiative to reduce tooth decay. ${ }^{1}$

Since 1990 the World Health Organisation (WHO) has recommended that intake of 'free sugars' should be less than $10 \%$ of total calorie intake. Free sugars are those that are added to food as well as those naturally present in honey, syrups, fruit juices and fruit concentrates.

The Newcastle University study, commissioned by the WHO and published last month in the Journal of Dental Research, recognises the benefit of this threshold by showing that when less than $10 \%$ of total calories in the diet is made up of free sugars there are much lower levels of tooth decay. The new research findings go even further, suggesting that halving this threshold for sugars to less than 5\% of calories - around five teaspoons a day - would bring further benefits, minimising the risk of dental cavities throughout life.

Professor Moynihan, Professor

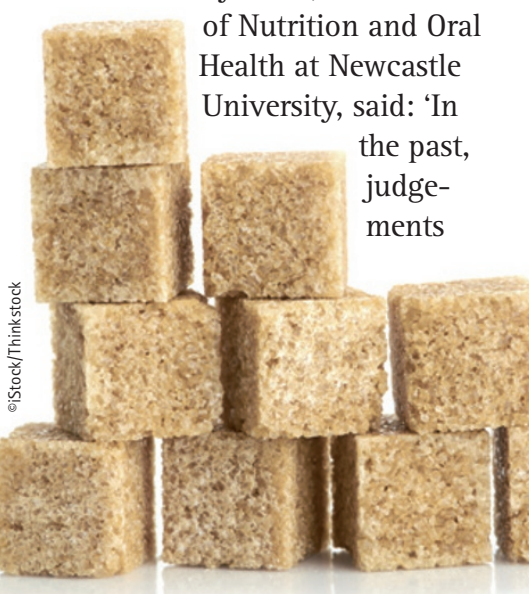
of Nutrition and Oral Health at Newcastle University, said: 'In the past, judge- on recommended levels of free sugars intake were made based on levels associated with an average of three or fewer decayed teeth in 12-year-olds. However, tooth decay is a progressive disease - by looking at patterns of tooth decay in populations over time, we now know that children with less than three cavities at age 12, go on to develop a high number of cavities in adulthood'.

The researchers scrutinised all the studies that had looked at relationships between amounts of sugars consumed and levels of dental caries. They found 55 relevant studies worldwide, dating back to 1950 . Combined analysis of the data was limited because of the variation in how the data were reported but there was strong consistency across studies and evidence of a large size effect.

Considering the studies which examined the influence of fluoride, the researchers found that while it does protect teeth, people living in areas with fluoridated water and/or using fluoride toothpaste still got dental caries.

Professor Moynihan concluded: 'We need to make it easier for people to make healthier choices when it comes to sugars by ensuring that options lower in added sugars are made widely available in schools, shops and the workplace'.

1. Moynihan P J, Kelly S A. Effect on caries of restricting sugars intake: systematic review to inform WHO guidelines. J Dent Res 2013; DOI: 10.1177/0022034513508954.

\section{NINTH YOUNG DENTIST CONFERENCE}

The ninth annual Young Dentist Conference will take place at the Royal College of Physicians in London on Saturday 8 February 2014.

The event, jointly organised by the British Dental Association, the BDJ and Dental Protection, is specifically directed to the needs of dentists in the early years of their career.

Chris O'Connor will explain how to facilitate quality adhesive dentistry in NHS primary care; Ken Harris will address the topic 'I thought my veneers were permanent?'; Surinder Poonian will provide tips for recently qualified dentists; and Paul Redmond, Director of Employability and Educational Opportunities at the University of Liverpool, will speak on the 'generation gap' and problems and risk arising from it.

For more information call 02073992914 or visit www.dentalprotection. org/newsnevents/events/uk/Young_Dentist_Conference2014. 